\title{
Generation of free convection due to changes of the local circulation
}

\section{system}

\author{
R. Eigenmann ${ }^{1}$, S. Metzger $^{1, *}$, and T. Foken ${ }^{1}$ \\ ${ }^{1}$ Department of Micrometeorology, University of Bayreuth, Bayreuth, Germany \\ * now at: Institute for Meteorology and Climate Research - Atmospheric Environmental Research (IMK-IFU), Karlsruhe \\ Institut of Technology, Garmisch-Partenkirchen, Germany
}

Received: 31 March 2009 - Published in Atmos. Chem. Phys. Discuss.: 7 May 2009

Revised: 29 October 2009 - Accepted: 5 November 2009 - Published: 12 November 2009

\begin{abstract}
Eddy-covariance and Sodar/RASS experimental measurement data of the COPS (Convective and Orographically-induced Precipitation Study) field campaign 2007 are used to investigate the generation of near-ground free convection conditions (FCCs) in the Kinzig valley, Black Forest, Southwest Germany. The measured high-quality turbulent flux data revealed that FCCs are initiated near the ground in situations where moderate to high buoyancy fluxes and a simultaneously occurring drop of the wind speed were present. The minimum in wind speed - observable by the Sodar measurements through the whole vertical extension of the valley atmosphere - is the consequence of a thermallyinduced valley wind system, which changes its wind direction from down to up-valley winds in the morning hours. Buoyancy then dominates over shear within the production of turbulence kinetic energy near the ground. These situations are detected by the stability parameter (ratio of the measurement height to the Obukhov length) when the level of free convection, which starts above the Obukhov length, drops below that of the sonic anemometer. An analysis of the scales of turbulent motions during FCCs using wavelet transform shows the occurrence of large-scale turbulence structures. Regarding the entire COPS measurement period, FCCs in the morning hours occur on about $50 \%$ of all days. Enhanced surface fluxes of latent and sensible heat are found on these days.
\end{abstract}

\section{Introduction}

The COPS (Convective and Orographically-induced Precipitation Study) field campaign was undertaken from 1 June to 31 August 2007 within the low mountain range of the

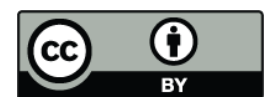

Correspondence to: R. Eigenmann (rafael.eigenmann@uni-bayreuth.de)
Black Forest, the Vosges Mountains and the Swabian Jura with the Rhine rift valley as a pronounced topographic lowland plain in between (Wulfmeyer et al., 2008). Rainfall in the COPS area is characterized by subgrid-scale convection initiation (CI) processes, e.g. orographically or thermallyinduced local circulation systems, triggered by the complex terrain, thus complicating the exact modeling and forecasting of precipitation events (Meißner et al., 2007; Barthlott et al., 2006). The problems of modeling convective clouds and precipitation - its time, amount and location - are the premature initiation of convection, the simulation of convective precipitation events as being too spatially widespread and the overestimation of precipitation on the windward compared to the lee side over low-mountain ranges, e.g. the Black Forest (Schwitalla et al., 2008).

The interaction of the land surface with the overlying atmosphere crucially affects the energy and water cycle over many temporal and spatial scales (Betts et al., 1996). The spatial distribution and patchiness of individual land use elements can have a strong impact on the atmospheric boundary layer (ABL) evolution and its thermodynamic structure, as changes of the surface energy budget directly influence the surface turbulent fluxes of moisture, momentum and heat, which act as the link between the atmosphere and the underlying soil-vegetation system (Pielke, 2001). Dynamical phenomena in the ABL can be related to changing surface characteristics, since gradients in sensible heat flux produced by evapotranspiration, albedo and soil property discontinuities induce local or secondary circulation systems (Segal and Arritt, 1992). Together with diurnal mountain winds developing over mountainous terrain (Whiteman, 1990), land surface-atmosphere interactions and the related physical processes within complex terrain are the key to the local occurrence and timing of the initiation of convection, cloud formation and precipitation (Hanesiak et al., 2004; Pielke, 2001; Chen and Avissar, 1994; Rabin et al., 1990; Banta, 1990, 1984; Raymond and Wilkening, 1980). Besides land-surface

Published by Copernicus Publications on behalf of the European Geosciences Union. 
interactions and orography, mesoscale and synoptic scale features are important for convective processes (Wulfmeyer et al., 2007). Kottmeier et al. (2008) discusses several mechanisms relevant for $\mathrm{CI}$ in the COPS region.

The present study aims at the detection and the description of near-ground free convection conditions (FCCs) by using eddy-covariance (EC) measurements. FCCs can be detected at the height of the EC measurement (see Sect. 2.1) close to the ground with the help of the stability parameter (see Sect. 3.2) and occur if the buoyancy term dominates over the shear term within the turbulence kinetic energy equation. In the case of detection of FCCs near the ground, convective elements are closely related to ground sources and can more effectively transport quantities of moisture, heat and trace gases enhanced in near-ground regions into the ABL. Moreover, following Shen and Leclerc (1995), the dimensions of our targeted land use type (corn field) of the EC measurements (see Sect. 2.1) are large enough (>250 m) that the surface fluxes are able to exert a major influence on $\mathrm{ABL}$ thermodynamics and turbulence structure.

Recently, Mayer et al. (2008) found that FCCs detected close to the bottom of a valley result in a strong and sudden ozone decrease at a mountain summit (Hohenpeissenberg) in the morning hours. In their study, the FCCs are triggered by a simultaneously occurring wind speed minimum, which reduces shear and leads to a dominance of buoyancy. On about half of the days these wind speed minima could be attributed to the onset of Alpine Pumping in the alpine foreland (Lugauer and Winkler, 2005) associated with a change of wind direction causing a drop of the horizontal wind speed. Hence, other mesoscale or local circulation systems initiated by complex terrain - e.g. the well known slope and valley winds in the Black Forest (Kossmann and Fiedler, 2000; Kalthoff et al., 2000) - are expected to trigger FCCs.

For that reason, the focus of the present study is to demonstrate the applicability of the EC method to the detection of FCCs in experimental data obtained during the COPS field campaign in the Kinzig valley (Black Forest), which was found in earlier studies (e.g., Meißner et al., 2007) to establish a pronounced diurnal thermally-induced valley wind system. Moreover, the processed turbulent flux data passing through a detailed quality assurance and control effort are used to select and describe these FCCs in detail.

\section{Materials and methods}

\subsection{Site description and experiment set-up}

During the COPS field campaign, a network of 17 energy balance and turbulence stations was set up over the entire COPS region (Wulfmeyer et al., 2007). The energy balance and turbulence station under investigation in the present study is located in the Kinzig valley near Fußbach $\left(48^{\circ} 22^{\prime} 7.8^{\prime \prime} \mathrm{N}, 8^{\circ} 1^{\prime} 21.2^{\prime \prime} \mathrm{E}, 178 \mathrm{~m}\right.$ a.s.l) on the western edge

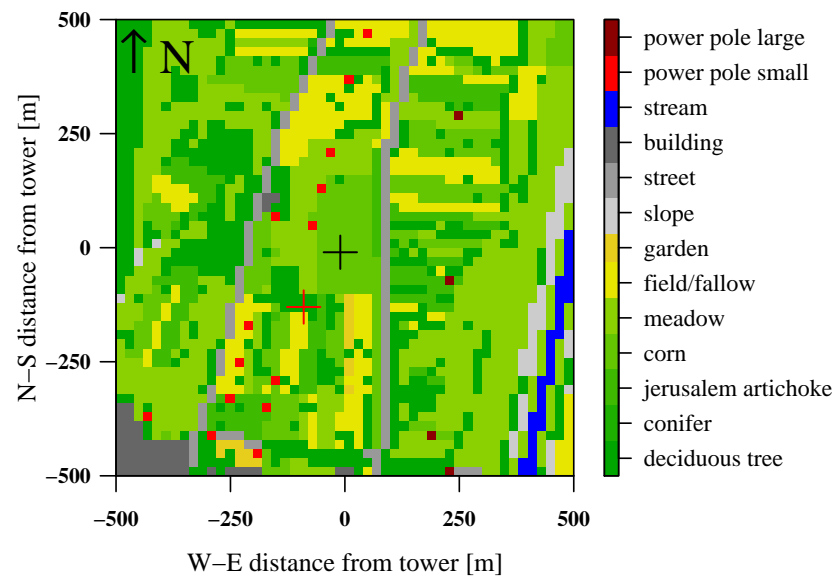

Fig. 1. Land use map $\left(1 \times 1 \mathrm{~km}^{2}\right)$ at the Fußbach site with the location of the eddy-covariance station indicated as a black cross in the middle of the map above the target land use type (corn). The additional red cross marks the position of the Sodar/RASS system. Fetch distances of the eddy-covariance system depending on wind sector can be obtained from Table 1 .

of the Black Forest, Southwest Germany. The Kinzig valley at Fußbach is oriented in a N-S direction, thus specifying the main wind direction, and has a valley width of about $1.3 \mathrm{~km}$. Mountain crests in the immediate vicinity of the Fußbach site reach maximal values of about $450 \mathrm{~m}$ a.s.l. The target land use type was a corn field (length: $260 \mathrm{~m}$, width: $140 \mathrm{~m}$ ) located within the patchy, agricultural land use of the Kinzig valley (see Fig. 1).

In this study, data of an EC tower and a nearby Sodar/RASS system are used. The EC system (measurement height: $2.29 \mathrm{~m}$, sampling rate: $20 \mathrm{~Hz}$ ) measured turbulent fluxes of momentum, sensible and latent heat as well as carbon dioxide $\left(\mathrm{CO}_{2}\right)$ above the corn field using a CSAT3 (Campbell Scientific, Inc.) sonic anemometer for recording the wind vector and the sonic temperature $T_{S}$ and a LI-7500 (LI-COR Biosciences) open-path gas analyser for water vapor $\left(\mathrm{H}_{2} \mathrm{O}\right)$ and $\mathrm{CO}_{2}$ concentrations. The Sodar/RASS system consisted of a phase array Doppler Sodar DSDPA.90-64 with a $1290 \mathrm{MHz}$ RASS extension by Metek $\mathrm{GmbH}$ and provided vertical profiles of wind velocity components, wind direction and acoustic temperature with a vertical resolution of $20 \mathrm{~m}$ and a temporal resolution of $10 \mathrm{~min}$. More detailed information about the measuring set-up and background data can be obtained from Metzger et al. (2007).

\subsection{Quality control effort}

The EC flux data measured at the Fußbach site was processed and quality controlled applying the latest micrometeorological post-field data processing standards (e.g., Mauder et al., 2006) in order to obtain a data set of the desired quality and accuracy, which can be utilized for further fundamental 
research. Accordingly, the turbulent flux raw data recorded with the EC method was post-processed with the comprehensive software package TK2 developed at the University of Bayreuth (Mauder and Foken, 2004), which comprises state of the art flux corrections and post-field quality control including tests on the fulfillment of integral turbulence characteristics and stationarity (Foken and Wichura, 1996; Foken et al., 2004).

Theoretical assumptions actually restrict the EC method to homogeneous terrain, but the increasing requirement for continuous monitoring of flux data (Aubinet et al., 2000; Baldocchi et al., 2001) forced the application of the EC method within highly structured terrain such as that in the COPS region. This step is supported by the development of a site evaluation and characterisation approach (Göckede et al., 2004, 2006), which combines the flux data quality approach (Foken et al., 2004) with a forward Lagrangian footprint model (Rannik et al., 2000, 2003). The approach is able to identify site-specific spatial quality structures and the spatial representivity of the measured flux data in the context of the underlying land use distribution and has been recently employed on sites of the CarboEurope network by Rebmann et al. (2005) and Göckede et al. (2008). In this study, it is used - together with an internal boundary layer evaluation procedure - in order to obtain target land use typerepresentative turbulent flux data sets of the required high quality usable for further analyses. The check for possible internal boundary layers, which form as a consequence of changes of the underlying surface characteristics, is implemented by using the following fetch-height relation to roughly estimate the height of the new equilibrium layer $\delta$ depending on fetch $x$ (Raabe, 1983; Jegede and Foken, 1999) neglecting weak stability effects (Savelyev and Taylor, 2005):

$z_{a} \leq \delta=0.3 \sqrt{x}$

The aerodynamic measurement height $z_{a}$ should be lower than $\delta$ in order to guarantee that the EC measurement takes place within the new equilibrium layer establishing over the target land use type.

\subsection{Spectral analysis}

Spectral analysis methods are used in this paper to study the temporal scales of the turbulence during the period of FCCs (see Sect. 3.2). Methods used are the continuous wavelet transform (CWT) and the computation of power spectra, both applied to the time series of EC raw data of the vertical wind speed, the horizontal wind speed components and the sonic temperature from 05:00 to 13:00 UTC.

To prepare data for the CWT, the time series were block averaged from the original $20 \mathrm{~Hz}$ raw data to a sampling frequency of $0.5 \mathrm{~Hz}$ in order to drastically reduce computational time of the CWT without altering the results significantly (e.g., Thomas and Foken, 2005) as the decisive scales range in the order of several seconds to a few minutes. Subsequently, all block averaged time series apart from the vertical wind speed (no trend removal necessary) have been detrended using polynomial regression. The resulting high-pass filtered time series is obtained by substracting the fitted polynomial from the block averaged time series. The residual time series is used for the calculation of the CWT using the Morlet wavelet. The CWT and plotting routine of the normalized wavelet power spectra was done by using the software package sowas (software for wavelet spectral analysis and synthesis: Maraun and Kurths, 2004; Maraun et al., 2007) implemented in the statistical computing software R. Results of a pointwise significance test (significance level: 0.95) performed by Monte Carlo simulations (1000 realizations) are indicated by black solid lines in the plots of the normalized wavelet power spectra.

The calculation of the power spectra of detrended (by polynomial regression) and tapered $20 \mathrm{~Hz}$ time series of the vertical wind speed, the longitudinal wind speed and sonic temperature before, during and after the period of FCCs within the time range from 05:00 to 13:00 UTC was realized by applying a fast Fourier transform (FFT) to the computed autocorrelation function. Smoothing of the raw periodogram was performed using a modified Daniell smoother window technique.

\section{Results and discussion}

\subsection{Quality control of the turbulent flux measurements}

This section presents some results of the detailed quality control effort adapted to the eddy-covariance flux data as described in Sect. 2.2.

Processed turbulent fluxes of sensible $\left(Q_{H}\right)$ and latent heat $\left(Q_{E}\right)$, friction velocity $u_{*}$ as well as the $\mathrm{CO}_{2}$ net ecosystem exchange $N E E$ are depicted in Fig. 2 as Hovmøller-type plots where the color bar on the right side represents the calculated values with white areas indicating data failure $(9.9 \%$ for each flux).

Furthermore, footprint analysis (see Sect. 2.2) were performed according to the site evaluation and characterisation approach of Göckede et al. (2004, 2006). To gain insight into the average flux contribution over the entire measurement period of the target land use type "corn" as a function of different wind sectors and stability classes, appropriate sorted data have been individually processed within the footprint analysis procedure. The results are listed in Table 1 and reveal good average flux contributions of more than $92 \%$ for all wind sectors during unstable or neutral cases. However, for stable stratification easterly and westerly sectors have to be considered critically, as flux contributions below $80 \%$ can be found, with the minimum $(67 \%)$ in the $240^{\circ}$ wind sector. Admittedly, the latter finding has to be regarded with the knowledge that the density of available data is low in the 
Table 1. Average flux contribution [\%] from the target land use type "corn" depending on wind sector and stability class at Fußbach. Moreover, the internal boundary layer evaluation procedure for average conditions over the entire measurement period is depicted. The internal boundary layer height $\delta$ calculated according to Eq. (1) with fetch $x$ are listed in dependence of the 12 wind sectors distinguished. Wind sectors where $\delta$ falls below the average aerodynamic measurement height $z_{a}=2.29 \mathrm{~m}$ are flagged by "X".

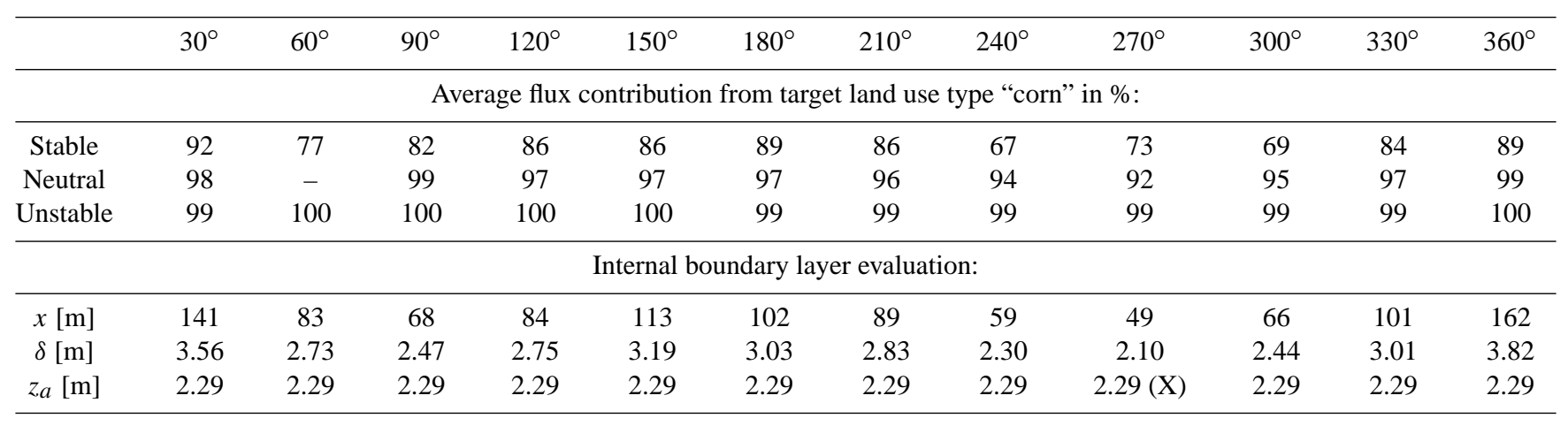

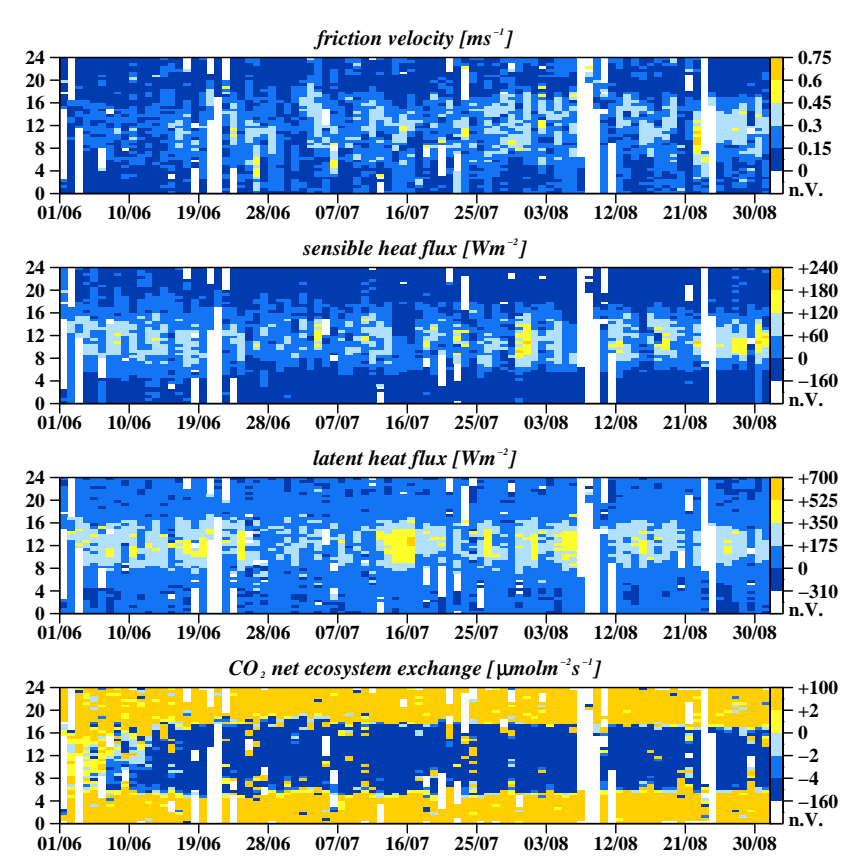

Fig. 2. Friction velocity $u_{*}\left[\mathrm{~ms}^{-1}\right]$, sensible heat flux $Q_{H}\left[\mathrm{Wm}^{-2}\right]$, latent heat flux $Q_{E}\left[\mathrm{Wm}^{-2}\right]$ and $\mathrm{CO}_{2} N E E$ $\left[\mu \mathrm{molm}^{-2} \mathrm{~s}^{-1}\right]$ for the entire COPS measurement period at Fußbach. X-axis represents the day of the year, Y-axis the time of the day [UTC] and the attached color bar the calculated values, where $n . V$. indicates data failure.

easterly and westerly wind sectors as these do not lie within the main wind direction, thus weakening its influence on the overall assessment.

The results of the internal boundary layer evaluation of the eddy-covariance flux data as described in Sect. 2.2 are also depicted in Table 1, and are illustrative of average conditions over the entire measurement period and for the 12 wind sectors distinguished. Referring to Table 1 , the $270^{\circ}$ sector shows a greater aerodynamic measurement height $z_{a}$ compared to the height of the new equilibrium layer $\delta$, thus indicating that the flux measurements within this sector cannot be associated with the target land use type "corn" regarding average conditions over the entire measurement period. Also the data of the $240^{\circ}$ sector should be discarded, as $\delta$ is in the same range as $z_{a}$ indicating disturbed conditions.

The closure of the surface energy balance was also checked for the Fußbach site by plotting the sum of the turbulent fluxes $Q_{H}$ and $Q_{E}$ of each half-hourly measurement against the corresponding available energy $\left(-Q_{S}^{*}-Q_{G}\right)$ values, where $-Q_{S}^{*}$ is the net radiation and $Q_{G}$ the ground heat flux. The heat storage in the upper soil layer for the calculation of $Q_{G}$ was considered applying the "simple measurement" method after Liebethal and Foken (2007). A regression analysis revealed an average non-closure of $20.4 \%$ for the period of the entire COPS field campaign. The imbalance can primarily be attributed to the landscape heterogeneity assignable to the COPS region inducing unconsidered low-frequency flux contributions and advective flux components (Foken, 2008a; Foken et al., 2006). Indeed, large-eddy simulation studies recently revealed that turbulent organized structures (Kanda et al., 2004; Steinfeld et al., 2007) and secondary circulations (Inagaki et al., 2006) have an influence on the surface energy balance closure.

\subsection{Generation of free convection at COPS IOP8b}

The measurement of high-quality surface turbulent fluxes led to the detection of near-ground free convection conditions (FCCs) in the morning hours, not only at the site under investigation in this study (Fußbach), but also at other sites of the COPS energy balance and turbulence network (Eigenmann, 
2008). Preliminary graphics produced in combination with routine data quality control during the COPS field phase consolidated recently observed indications (Mayer et al., 2008) that thermally-driven circulation systems may trigger FCCs in the morning hours, at times when the existing circulation system changes its previously prevailing wind direction. In the Kinzig valley a pronounced valley circulation system can frequently be observed to be generated in high-pressure situations with high solar radiation and weak synoptic forcing. At COPS IOP8b (15 July 2007) - outlined in this section as a paradigm for the generation of FCCs at Fußbach - the Sodargramm of the wind direction in Fig. 3a illustrates the cessation of the down-valley, southerly winds which prevail at night and the onset of up-valley, northerly blowing winds at about 08:30 UTC near the ground. During this transition period, a strong drop of the horizontal wind speed through the whole vertical extension of the valley atmosphere lasting from 06:50 until 08:50 UTC in the morning hours, with values smaller than $1.5 \mathrm{~ms}^{-1}$, is evident from Sodar measurements (Fig. 3b).

The occurrence of FCCs can be detected by the EC flux measurements by calculating the stability parameter $\zeta$ according to the following equation:

$\zeta=\frac{z}{L}=-\frac{z \cdot \kappa \cdot g \cdot\left(\overline{w^{\prime} \theta_{v}^{\prime}}\right)_{0}}{\overline{\theta_{v}} \cdot u_{*}^{3}}$

where $z$ denotes the measurement height, $L$ the Obukhov length, $u_{*}$ the friction velocity, $g$ the acceleration due to gravity, $\overline{\theta_{v}}$ the mean virtual potential temperature, $\left(\overline{w^{\prime} \theta_{v}^{\prime}}\right)_{0}$ the buoyancy flux at the surface and $\kappa$ the von-Kármán constant $(\kappa \approx 0.4)$. FCCs are indicated for $\zeta<-1$ (Foken, 2008b) as, according to Arya (2001), $\zeta$ is equal to the flux Richardson number $R_{f}$ during unstable stratification $\left(R_{f}<0\right)$, which in turn is the quotient of the buoyancy term $(B)$

$B=\frac{g}{\overline{\theta_{v}}} \cdot\left(\overline{w^{\prime} \theta_{v}^{\prime}}\right)_{0}$

to the shear term $(S)$

$S=-\overline{u^{\prime} w^{\prime}} \cdot \frac{\partial \bar{u}}{\partial z}$

of the turbulence kinetic energy equation. Consequently, $\zeta<-1$ indicates that buoyancy created turbulence dominates over shear created turbulence and that FCCs occur near the ground. The shear term $S$ is the product of the momentum flux $\overline{u^{\prime} w^{\prime}}$ and the wind shear $\partial \bar{u} / \partial z$. Regarding the equation of $\zeta$ (Eq. 2), low values of $u_{*}$ and high buoyancy fluxes will support the occurrence of FCCs. In the Kinzig valley, a powerful trigger mechanism for the occurrence of FCCs is provided by the change of the valley circulation system in the morning (Fig. 3a), which leads to a drop of the wind speed (and $u_{*}$ by implication) near the ground (Fig. $3 \mathrm{~b}$ ) and thus to the domination of $B$ over $S$ and to $\zeta<-1$.
In Fig. 4a, the stability parameter $\zeta$ is depicted for COPS IOP8b, where the averaging period of the EC flux measurements (Fig. 4a-4f) was reduced from the standard $30 \mathrm{~min}$ to $5 \mathrm{~min}$ in order to enhance the temporal resolution. Data quality is good during the period of FCCs with quality flags after Foken et al. (2004) ranging from 1 to 3 within the 30 min data, $100 \%$ flux contribution from the target land use type "corn" and no disturbance due to internal boundary layers. Referring to Fig. 4a, FCCs with low values of $\zeta$ at 07:35-07:40 UTC correspond exactly to a $5 \mathrm{~min}$ duration local minimum of $u_{*}\left(0.04 \mathrm{~ms}^{-1}\right)$ in Fig. $4 \mathrm{c}$ triggering the FCCs. Another period of FCCs, which can be detected from 08:10-08:40 UTC, shows stability parameter values up to $\zeta=-1.4$ and also coincides with a local minimum of $u_{*}\left(0.09 \mathrm{~ms}^{-1}\right)$. Simultaneously, moderate values of $Q_{H}$ (Fig. 4d) are found around the times of the FCCs $\left(54.7 \mathrm{Wm}^{-2}\right.$ at 08:25 UTC). Lower friction velocities $u_{*}$ in general occur between 06:50 and 08:50 UTC explaining the generally small values of $\zeta$ and the occurence of FCCs during the period from 07:35 to 08:40 UTC (black dotted lines in Fig. 4a-h). In addition, Fig. 4h depicts the available energy at the ground $\left(-Q_{S}^{*}-Q_{G}\right)$ for the portioning into $Q_{H}$ (Fig. 4d) and $Q_{E}$ (Fig. 4d), which can be expressed as the Bowen ratio $B o$ (Fig. 4f). Bo has its highest values (0.59 at 06:35 UTC) shortly before the period of FCCs demonstrating a preferred transformation of the available surface energy ( $310 \mathrm{Wm}^{-2}$ during the period of FCCs) into $Q_{H}$. The lowered values of $\zeta$ at about 18:00 UTC (see Fig. 4a) cannot be related with FCCs as values of $Q_{H}$ are around zero $\left(-10<Q_{H}<10 \mathrm{Wm}^{-2}\right.$, see Fig. $\left.4 \mathrm{~d}\right)$ and data quality is very low (not shown).

Other parameters such as the ratio of the Deardorff velocity $w_{*}$ (Deardorff, 1970a,b)

$w_{*}=\left[\frac{g \cdot z_{i}}{\overline{\theta_{v}}} \cdot\left(\overline{w^{\prime} \theta_{v}^{\prime}}\right)_{0}\right]^{1 / 3}$

to the friction velocity $u_{*}$ confirm their capability to denote FCCs (see Fig. 4e), where the depth of the boundary layer $z_{i}$ is determined by visual inspection of a secondary maximum in the reflectivity profiles of the Sodar measurements (Beyrich, 1997). General difficulties in $z_{i}$ determination within complex terrain (Staudt, 2006; Kalthoff et al., 1998; Kossmann et al., 1998) and the high background noise of the nearby street at the Fußbach measurement site complicate the evaluation of the Sodar data. On most days, no clear secondary maximum of reflectivity can be found for the daytime boundary layer evolution, thus making the determination of $z_{i}$ a rough estimate rather than an exact determination. However, Fig. $3 \mathrm{c}$ shows the measured reflectivity of the Sodar/RASS complex, together with the determined evolution of $z_{i}$ in the morning hours between 04:00-11:40 UTC indicated as black points, thus enabling the calculation of $w_{*}$ and the subsequent display of $w_{*} \cdot u_{*}^{-1}$ in Fig. $4 \mathrm{e}$ at the same time. 

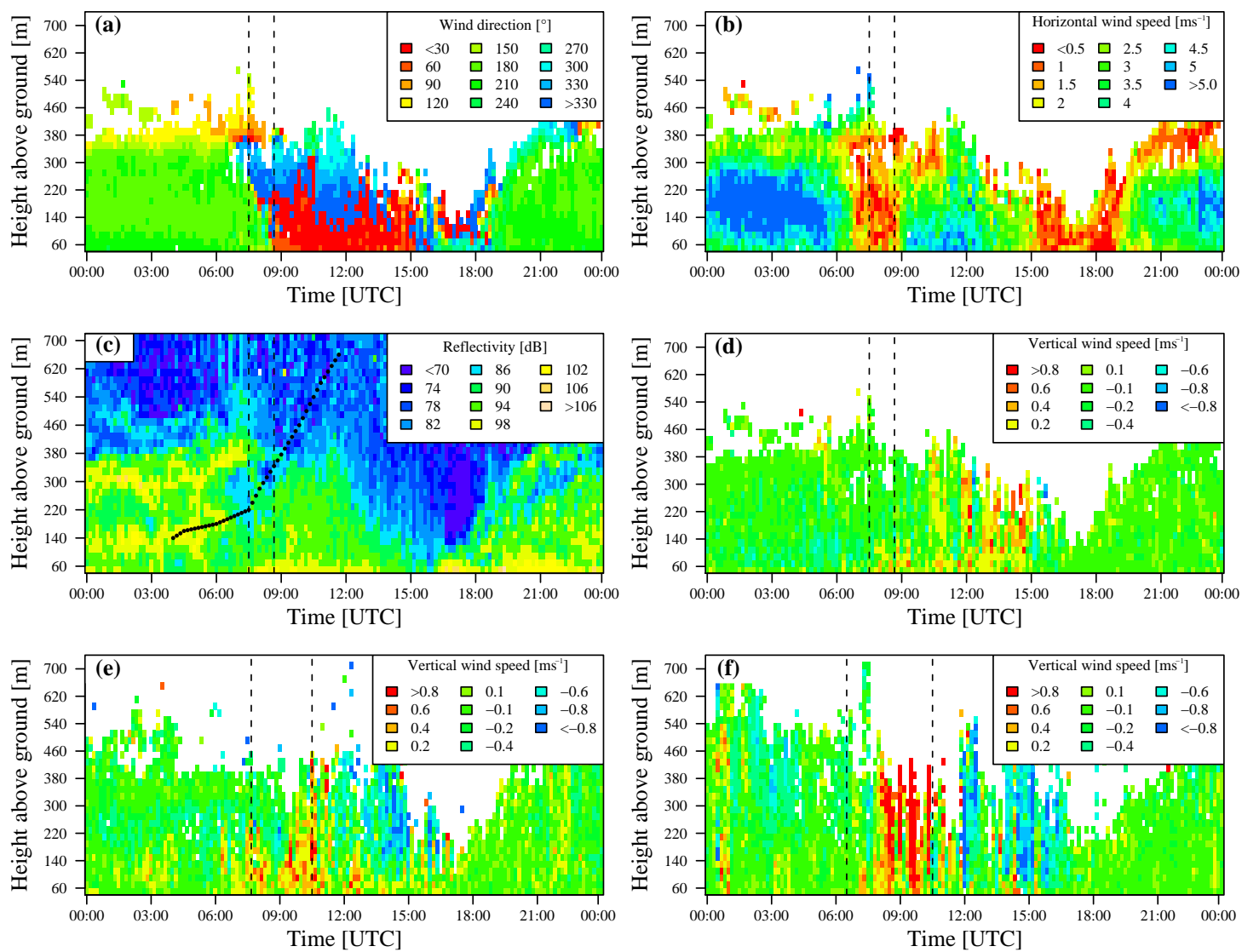

Fig. 3. Sodargramms of the wind direction $\left[^{\circ}\right](\mathbf{a})$, horizontal wind speed $\left[\mathrm{ms}^{-1}\right](\mathbf{b})$, reflectivity $[\mathrm{dB}](\mathbf{c})$ and vertical wind speed $\left[\mathrm{ms}^{-1}\right]$ (d) for COPS IOP8b at Fußbach. Also plotted are the vertical wind speed $\left[\mathrm{ms}^{-1}\right]$ for COPS IOP15a (e) and COPS IOP15b (f) at Fußbach. The black dashed lines in each figure indicate the periods of FCCs in the morning hours: 07:35-08:40 UTC at IOP8b (see Fig. 4a), 07:4510:35 UTC at IOP15a and 06:30-10:35 UTC at IOP15b. The black points in (c) represent the evolution of the boundary layer depth $z_{i}$ between 04:00 and 11:40 UTC determined by visual inspection of a secondary maximum in the reflectivity profile.

Moreover, the ratio $B \cdot S^{-1}$ - calculated according to Eq. (3) and (4) - can be used directly to detect FCCs (see Fig. 4g). The wind shear $\partial \bar{u} / \partial z$, necessary for the calculation of $S$, was determined with the wind speeds at 4 and $9 \mathrm{~m}$ a.g.l. measured with the cup anemometers of an additionally installed profile mast at the corn field. Considering a canopy height of $2.31 \mathrm{~m}$ at COPS IOP8b results in aerodynamic measurement heights $z_{a}$ of $2.46 \mathrm{~m}$ and $7.46 \mathrm{~m}$, respectively. The remarkable minima in Fig. $4 \mathrm{~g}$ at the times of the FCCs (07:35-08:40 UTC) underlines that the turbulence is mainly driven by buoyancy $(B)$ rather than shear $(S)$. The threshold of -3 (red dashed line in Fig. 4g) is chosen according to Stull (2000), which states favourable conditions for the generation of free convection for $|B|>|3 \cdot S|$.

So far, parameters indicating the occurrence of FCCs near the ground have been presented, but the impact these FCCs exert on boundary layer thermodynamics and structure has not been discussed yet.
A measure for convective activity in the ABL can be provided by our data set by the vertical wind speed measured with the Sodar/RASS complex (Fig. 3d-f). At COPS IOP8b, no increased upward vertical wind speeds can be found in the ABL during the period of FCCs (07:35-08:40 UTC, see Fig. 3d), but the onset of the first enhanced upward vertical wind speeds $\left(0.2-0.6 \mathrm{~ms}^{-1}\right)$ can be observed close to the ground up to $140 \mathrm{~m}$. However, this finding has to be considered with the knowledge that plume-like structures of rising air masses are a local phenomenon surrounded by areas of downdrafts (Stull, 1988). As the EC and Sodar/RASS measurement systems are spatially separated by about $170 \mathrm{~m}$ over different land use types (see Fig. 1) and the Sodar/RASS complex itself has a limited spatial and temporal resolution (10 min), it is clear that enhanced vertical wind speeds cannot be detected during each period of FCCs. On other days, however, the periods of FCCs detected close to the ground in the morning hours can be related to increased upward vertical 

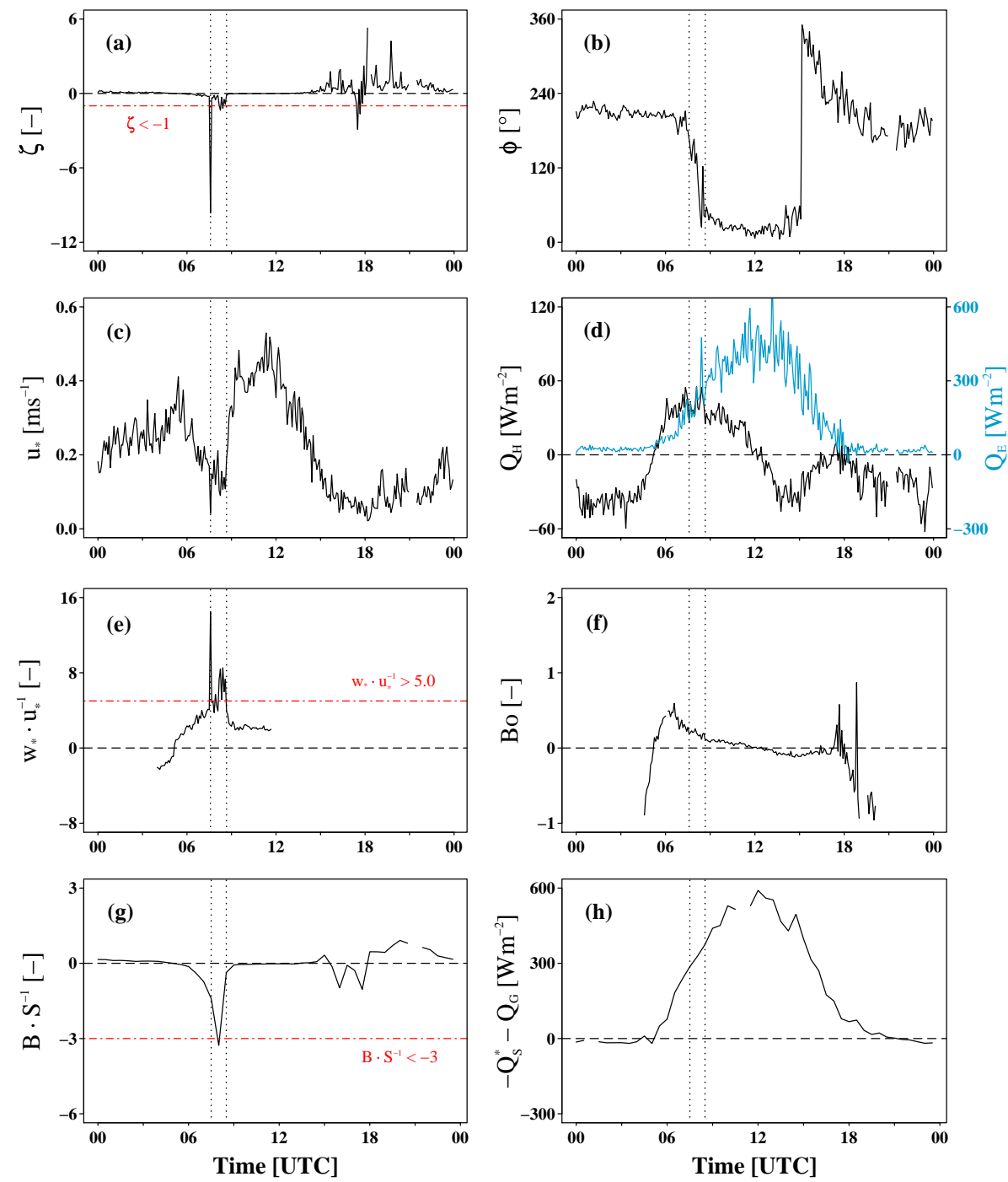

Fig. 4. Stability parameter $\zeta[-](\mathbf{a})$, wind direction $\phi\left[^{\circ}\right](\mathbf{b}), u_{*}\left[\mathrm{~ms}^{-1}\right]$ (c), $Q_{H}$ and $Q_{E}\left[\mathrm{Wm}^{-2}\right](\mathbf{d}), B \cdot S^{-1}[-]$ (a), available energy $-Q_{S}^{*}-Q_{G}\left[\mathrm{Wm}^{-2}\right]$ (b), $w_{*} \cdot u_{*}^{-1}[-]$ (c) and $B o[-]$ (d) for COPS IOP8b at Fußbach. The black dotted lines in each graph indicate the period of FCCs in the morning hours (07:35 UTC to 08:40 UTC) detected by the low values of $\zeta$.

wind speeds within the whole vertical extension of the ABL. As an example, the Sodargramms of the vertical wind speed at the high-pressure situations COPS IOP15a (12 August 2007) and IOP15b (13 August 2007) are shown in Fig. 3e and $3 \mathrm{f}$, respectively, which both show strong enhanced vertical wind speeds of locally more than $0.8 \mathrm{~ms}^{-1}$ within the 10 min averaged values during the periods of FCCs.

Furthermore, the coherent structure of plume-like upward motions at COPS IOP8b can be assumed when regarding the turbulent time series of vertical wind speed, sonic temperature, humidity and carbon dioxide (not shown) as visual inspection of them during the period of FCCs clearly reveals ramp-like structures typical for coherent turbulent exchange (e.g., Gao et al., 1989; Bergström and Högström, 1989).
To explicitly investigate the turbulence structure during the period of FCCs at COPS IOP8b, spectral analysis of the measured high-frequency turbulent time series (see Sect. 2.3) is utilized to reveal the scales of inherent turbulent eddies. Therefore, Fig. 5a and 5b show the normalized wavelet power spectra of the vertical wind speed and sonic temperature, respectively, where the temporal section on the X-axis ranges from 05:00 to 13:00 UTC (480 $\mathrm{min})$. It is obvious from the normalized wavelet power spectrum of the vertical wind speed (Fig. 5a), that during the period of FCCs (07:35-08:40 UTC) - marked by the black dotted vertical lines - a clear shift of significant areas of enhanced spectral power from high-frequency turbulence scales towards scales of lower frequency occurs. In particular, scales in the range 

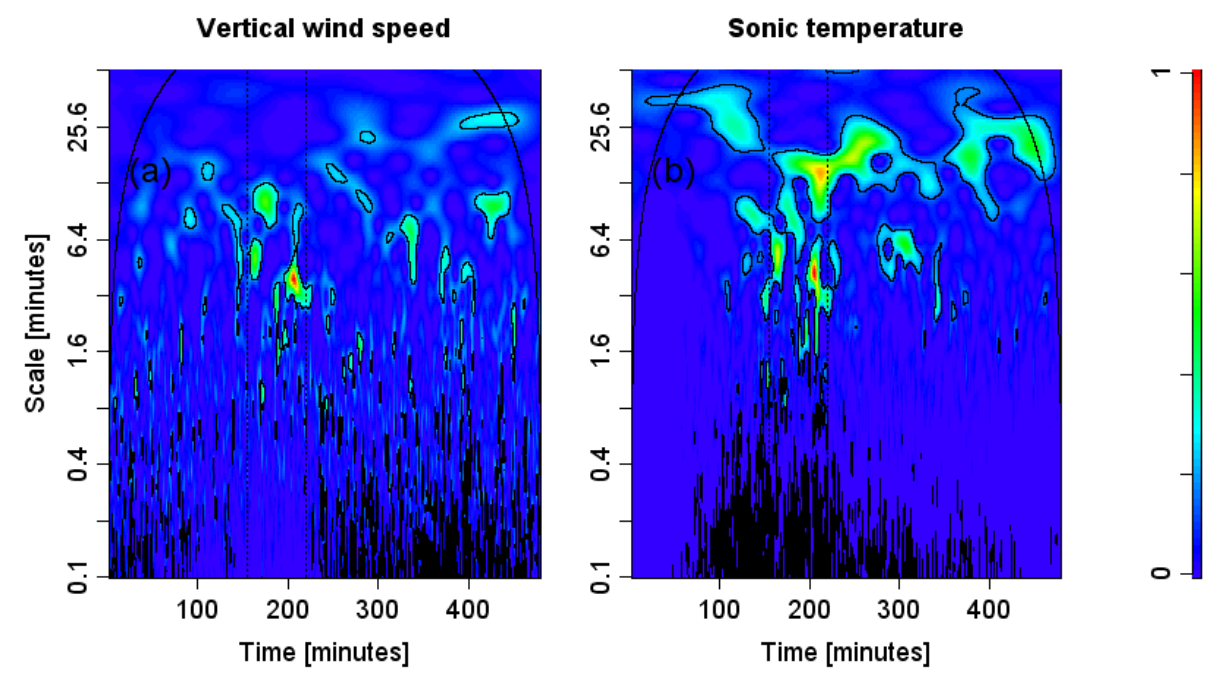

Fig. 5. Normalized wavelet power spectra of the vertical wind speed (a) and sonic temperature (b) from 05:00-13:00 UTC (480 min) for COPS IOP8b at Fußbach. The period of FCCs in the morning hours from 07:35-08:40 UTC is indicated by the black dotted vertical lines. The results of a pointwise significance test (significance level: 0.95$)$ performed by Monte Carlo simulations (1000 realizations) are also shown in the plots marked by black solid lines. The cone of influence is visible as a black curved line in the upper part of both plots.
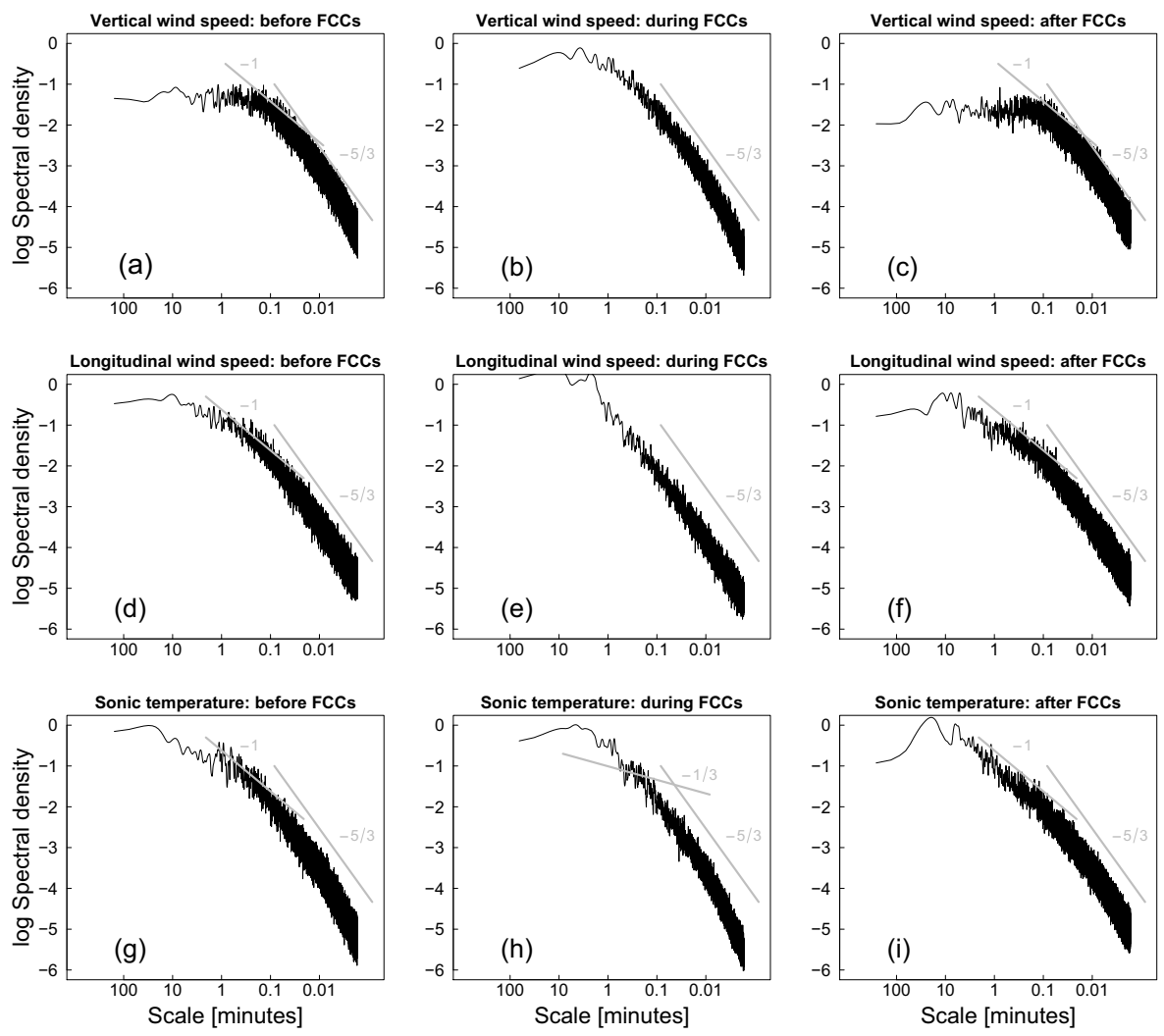

Fig. 6. Power spectra of the vertical wind speed (a-c), longitudinal wind speed (d-f) and sonic temperature (g-i), before (05:00-07:35 UTC), during (07:35-08:40 UTC) and after (08:40-13:00 UTC) the period of FCCs for COPS IOP8b at Fußbach. The chosen time periods coincide with those distinguished in Fig. 5 by the black dotted vertical lines. The gray solid lines indicate the $-5 / 3,-1$ and $-1 / 3$ power laws. 
of 1 to 7 min experience an enormous gain in spectral power during the period of FCCs. These time scales can be associated with the time $t_{*}$ it takes for air in plumes or thermals to cycle once between the bottom and the top of the mixed layer which is stated, e.g. in Stull (1988), to range in the order of 5 to $15 \mathrm{~min}$ in the case of a well developed convective boundary layer $(\mathrm{CBL})$. Considering the time of occurrence of the period of FCCs early in the morning hours within a growing CBL (see Fig. 3c) which inhibits larger circulation structures, our findings seem to be in good accordance with the textbook values. In our case, the average time scale $t_{*}=z_{i} \cdot w_{*}^{-1}$ during the period of FCCs $(07: 35-08: 40$ UTC) - calculated with an average $z_{i}$ of $285 \mathrm{~m}$ (see Fig. 3c) and an average $w_{*}$ of $0.75 \mathrm{~ms}^{-1}$ (see Fig. $4 \mathrm{c}$ and $4 \mathrm{e}$; values of $w_{*}$ in the order of 1 to $2 \mathrm{~ms}^{-1}$ are given, e.g. in Stull, 1988) - amounts to $t_{*}=$ $6.3 \mathrm{~min}$.

Figure $5 \mathrm{~b}$ also depicts the normalized wavelet power spectrum of the sonic temperature, which shows a slightly different behavior compared to that of the vertical wind speed (Fig. 5a) discussed above. Spectral power during the period of FCCs is also enhanced within scales in the range of 1 to $7 \mathrm{~min}$ (a second maximum can be found at around $13 \mathrm{~min}$ ), but high-frequency turbulent scales are still present during the period of FCCs contrary to the finding in the normalized wavelet power spectrum of the vertical wind speed. A possible explanation might be that the highly fluctuating temperature field close to the strongly heated surface causes a non-correlation between the wind and temperature field and, consequently, a different turbulent regime within the highfrequency part of the vertical wind speed and the temperature during the period of FCCs.

Spectral characteristics of the turbulence during the period of FCCs at COPS IOP8b are further examined by plots of the computed power spectra (see Sect. 2.3) of the vertical wind speed (Fig. 6a-c), the longitudinal wind speed (Fig. 6df) and the sonic temperature (Fig. 6g-i), before (05:0007:35 UTC), during (07:35-08:40 UTC) and after (08:4013:00 UTC) the period of FCCs. All depicted power spectra clearly show Kolmogorov's $-5 / 3$ power law (Kolmogorov, 1941) within a subset in the inertial subrange. However, at lower frequencies, towards production scales, the shape of the spectra should depend on atmospheric stability as demonstrated, e.g. in Monin and Yaglom (1975, Chap. 8), with experimental results of Gurvich $(1960,1962)$ and Zubkovskii (1962), who found that wind velocity spectra satisfy the $-5 / 3$ power law over a certain region, but show a clear dependence on different values of the Richardson number at the lower limit of the inertial subrange. Similar experimental results have been reported, e.g. by Kaimal et al. (1972), who showed that normalized velocity and temperature spectra converge within the inertial subrange corresponding to Kolmogorov's power law, but spread out depending on $\zeta$ at the lower frequency part of the spectra. In accordance to the studies mentioned above, our computed power spectra, especially that of the vertical (Fig. 6a-c) and longitudinal (Fig. 6d-f) wind speed, experience an appreciable gain of spectral power within time scales greater than $0.5 \mathrm{~min}$ during the period of FCCs compared to the power spectra before and after the period of FCCs characterized by near-neutral conditions. It is obvious that the scale of maximal spectral power of the vertical wind speed during the period of FCCs (Fig. 6b), which is found at about $4 \mathrm{~min}$, coincides with the time scales of maximal power observed in the normalized wavelet power spectrum of the vertical wind speed (Fig. 5a). Moreover, the study of Katul et al. (1995) is used to gain more insight into the spectral characteristics within the low-frequency part of our power spectra concerning a possible existence of a -1 power law and its deviation due to buoyancy. Katul et al. (1995) reported a -1 power law evident in the vertical and longitudinal wind speed and in the temperature power spectra during near-neutral atmospheric stratification, which can more or less be confirmed considering our power spectra before and after the period of FCCs (Fig. 6a, c, d, f, g, i) where neutral conditions are present. It has to be mentioned that the existence of $a-1$ power law for the vertical wind speed in the neutral case was found by Katul et al. (1995) to be only of limited extent (in accordance with our findings) and its existence is also considered to be controversial in the discussion of Katul and Chu (1998). Considering now the behavior of the low-frequency spectral characteristics during the period of FCCs, it is noticeable that the existence of a $-5 / 3$ power law in the inertial subrange in the case of the vertical (Fig. 6b) and longitudinal (Fig. 6e) wind speed can be extended towards the production scales, which is also stated by Katul et al. (1995) for the free convection stability regime. In the case of the temperature power spectrum Katul et al. (1995) referred to the existence of $a-1 / 3$ power law which can only be confirmed for a limited region, considering our temperature power spectrum (Fig. 6h). Finally, it is worthwhile to point out that our definition of the free convection regime $(\zeta<-1)$ differs from that $(\zeta<-2)$ used in Katul et al. (1995), so that the power laws corresponding to the case of moderately unstable conditions $(0.14<\zeta<-1.3)$ in the sense of Katul et al. (1995), i.e. $\mathrm{a}-2$, $\mathrm{a}-1$ and $\mathrm{a}-1$ power law for the longitudinal and vertical wind speed and the temperature power spectra, respectively, may also be applied to our data, as average stability values during our period of FCCs $(\zeta=-1.3)$ may also be associated with the upper edge of the moderately unstable regime of Katul et al. (1995). Nevertheless, to summarize our findings, the effect of FCCs on the spectral characteristics of the turbulence is clearly visible in our study.

\subsection{FCCs during the entire COPS measurement period}

Having outlined the generation of FCCs due to a change of the valley wind system in detail for COPS IOP8b within the previous section, the entire measurement period should now be regarded. At Fubach, 23 days, which make up 25\% of the 92 days observed in the COPS field campaign, can be 
Table 2. Mean onset and cessation times [UTC] of the up-valley wind direction and the mean times of FCCs of those days classified as "event days", with standard deviation (SD), and number (n) for the individual months (June, July, August) and for the whole COPS measurement period at Fußbach.

\begin{tabular}{cccccccccccc}
\hline \multicolumn{3}{c}{ Onset of up-valley wind direction } & \multicolumn{3}{c}{ Cessation of up-valley wind direction } & \multicolumn{3}{c}{ FCCs } \\
\hline Period & Mean & SD & $\mathrm{n}$ & Period & Mean & SD & $\mathrm{n}$ & Period & Mean & SD & $\mathrm{n}$ \\
\hline June & $08: 01$ & $01: 14$ & 8 & June & $17: 36$ & $00: 55$ & 7 & June & $07: 33$ & $01: 08$ & 8 \\
July & $08: 03$ & $00: 37$ & 5 & July & $17: 23$ & $01: 35$ & 5 & July & $08: 14$ & $00: 51$ & 5 \\
August & $09: 06$ & $00: 46$ & 10 & August & $17: 56$ & $01: 10$ & 10 & August & $08: 48$ & $00: 42$ & 10 \\
whole & $08: 29$ & $01: 02$ & 23 & whole & $17: 42$ & $01: 10$ & 22 & whole & $08: 14$ & $01: 01$ & 23 \\
\hline
\end{tabular}

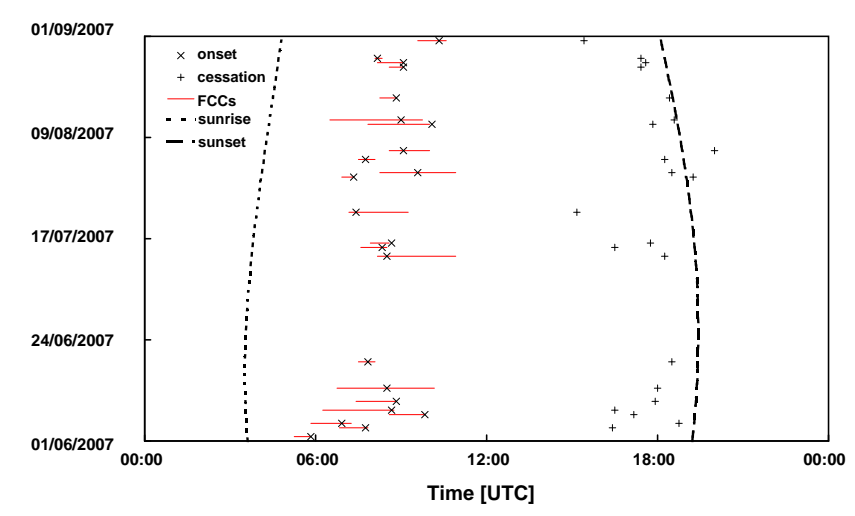

Fig. 7. Onset and cessation times of the up-valley wind direction and the corresponding periods of FCCs in the morning hours at days classified as "event days" regarding the entire COPS measurement period at Fußbach. Also depicted are the times of sunrise and sunset.

classified as "event days" coinciding with the paradigm of the generation of FCCs at COPS IOP8b outlined in Sect. 3.2. Furthermore, 19 days $(21 \%)$ can be denoted as "intermittent days", as they do not exhibit a clear diurnal, persistent valley wind circulation. FCCs occur but can only be attributed to brief duration - several minutes up to a few hours - changes from down-valley to up-valley winds during the day, these sometimes not even reaching a full wind rotation of $180^{\circ}$. Despite the fact that most of the FCCs of these "intermittent days" seem to be triggered by short changes of wind direction of varying duration, it was decided to separate the "intermittent" from the "event days" in order to have similar flow patterns initiating the FCCs and thus a clearly structured data set. The reason for the intermittence of the valley winds is a decrease of the solar energy input, e.g. due to cloud shading. Finally, 37 days (40\%) at Fußbach can be characterized as "non-event days", as FCCs do not appear. Thirteen days (14\%) cannot be evaluated due to data failure.

Figure 7 shows all days classified as "event days" (23) with the onset and cessation times of the up-valley wind direction, the periods in which FCCs occurred and the times of sunrise and sunset during the entire COPS campaign. The mean onset and cessation times of the up-valley wind direction and the mean times of FCCs of those days classified as "event days", with standard deviation and number, are listed in Table 2 for the individual months and the whole measurement period. Remarkable is the adjustment of the onset of the up-valley wind direction and of the FCCs to the seasonal change of sunrise evident in the mean values of the individual months. The mean duration of the periods in which FCCs occur - depicted in Fig. 7 - is 84 min with a standard deviation of $57 \mathrm{~min}$.

To clarify the difference of "event" and "intermittent days" as related to the diurnal valley wind system, persistence values $P$ were calculated from the west-east and south-north components ( $u$ and $v$, respectively) and the horizontal wind speed $v_{h}$ of the EC sonic anemometer following Lugauer and Winkler (2005):

$P(t)=\frac{\sqrt{\overline{u(t)}^{2}+\overline{v(t)}^{2}}}{\overline{v_{h}(t)}}$

where the temporal vector mean of the horizontal wind speed is divided by the arithmetic mean of the horizontal wind speed at every time of the day. $P$ can adopt values between 0 and 1 , where 1 means that every day at that time the wind blew from the same direction. Figure 8a depicts the calculated persistence $P$ for all days, "event days", "intermittent days" and "non-event days". Two pronounced eye-catching minima can be found the "event days", i.e. one at the times the up-valley winds start (at about 08:00 UTC) and another at the times the up-valley winds rotate back to down-valley winds (at about 18:00 UTC), indicating highly variable wind directions during these times. The $P$ values above 0.75 for the rest of the time point to a quasi-identical flow pattern on the 23 selected "event days" at Fußbach. The small persistence values of the "intermittent days" between 06:00 and 18:00 UTC can be attributed to the non-persistence of the up-valley winds, as briefly lasting up-valley winds are interrupted by frequent rotations back to the original wind direction due to a decrease of the solar energy input (through cloud shading) which otherwise usually drives constantly blowing up-valley winds. 

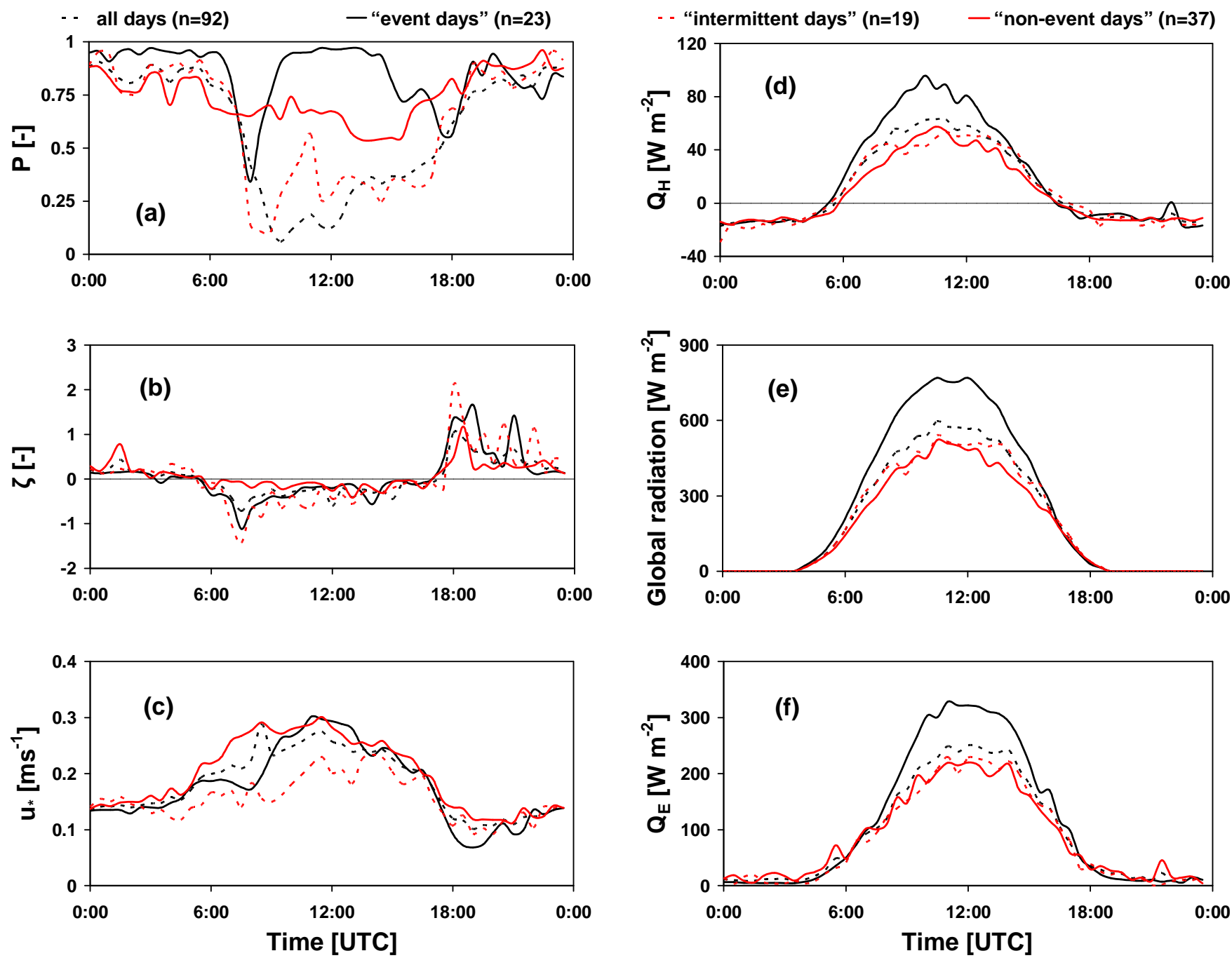

Fig. 8. Persistence $P[-]$ (a) and mean diurnal trends of the stability parameter $\zeta[-]$ (b), friction velocity $u_{*}\left[\mathrm{~ms}^{-1}\right]$ (c), sensible heat flux $Q_{H}\left[\mathrm{Wm}^{-2}\right]$ (d), global radiation $\left[\mathrm{Wm}^{-2}\right]$ (e) and latent heat flux $Q_{E}\left[\mathrm{Wm}^{-2}\right]$ (f) for all days of the COPS measurement period (92), days classified as "event days" (23), "intermittent days" (19) and "non-event days" (37) at Fußbach. Thirteen days cannot be classified due to data failure.

Mean diurnal trends of $\zeta$ (Fig. 8b), $u_{*}$ (Fig. 8c), $Q_{H}$ (Fig. 8d), global radiation (Fig. 8e) and $Q_{E}$ (Fig. 8f) of the individually classified days can be applied to characterize the FCCs. The mean values of $\zeta$ indicate the occurrence of FCCs in the morning hours at about 08:00 UTC on both "intermittent" and "event days". After this distinct minima of $\zeta$ at about 08:00 UTC (until about 12:00 UTC), the "intermittent days" show slightly lower values of $\zeta$, indicating that the intermittence of the valley wind system causes more frequent triggering of FCCs. A clear difference in the magnitude of $u_{*}$ comparing "event" and "non-event days" (see Fig. 8c) at about 08:00 UTC underlines that the drop of $u_{*}$ caused by the valley wind reversal in the morning hours triggers FCCs. The generally lower values of $u_{*}$ on the "intermittent days" can be explained by the non-persistence of the valley winds resulting in a continuous drop of the horizontal wind speed. Above-average values of $Q_{H}$ and global radiation (Figs. 8d and 8e) can be found on the "event days", thus indicating the preferred occurrence of FCCs in clear, undisturbed weather situations with high solar radiation driving the valley winds, which act as the trigger mechanism for FCCs by providing the necessary minimum of $u_{*}$ in the early morning transition period. Moreover, about $100 \mathrm{Wm}^{-2}$ higher $Q_{E}$ values (Fig. 8f) can be observed on the "event days" compared to the "non-event days", which also contribute, due to density effects, to the destabilization of near-ground air masses. 


\section{Conclusions}

A comprehensive quality assurance and control effort, including footprint analysis and a check for internal boundary layers, was adapted to the EC turbulence measurements at Fußbach in order to obtain high-quality surface flux data usable for the detection $(\zeta<-1)$ and description of FCCs in the Kinzig valley. FCCs were found to be triggered by a change of the local valley circulation system from down to up-valley winds in the morning hours and occurred on about half of the total 92 COPS days summing up days classified as "event" and "intermittent days". This frequent occurrence of FCCs confirms the assumption of Mayer et al. (2008) that other regions showing complex terrain - besides the alpine foreland investigated in their study - might face trigger mechanisms, such as local or mesoscale circulation systems leading to the convective release of near-ground air masses into the ABL. FCCs initiated by a change of the valley winds were also found by Hiller et al. (2008) in an alpine valley in Switzerland following their stability and data quality analysis. Unfortunately, these authors did not address these events. The large-eddy scale character of the turbulence near the ground during periods of FCCs could be confirmed by applying spectral analysis methods (see Figs. 5 and 6), thus suggesting that plume-like coherent structures of rising air masses emerge from the detected FCCs. These large-scale structures can more effectively transport quantities of heat and moisture enhanced in near-ground regions into the ABL. As enhanced surface fluxes of latent and sensible heat were found on the "event days" compared to "non-event days" (see Fig. 8) as well as increased upward vertical wind speeds in the Sodar measurements during FCCs (see Figs. 3e and 3f), a clear effect of the detected FCCs on the thermodynamic structure of the ABL is obvious. To sum up, FCCs are likely - in addition to other orographic or landscape effects - to have a non-negligible impact on ABL temperature and moisture profiles and to play a role for CI processes.

In order to directly simulate the impact of FCCs on ABL thermodynamics and on possibly subsequent cloud formation, a large-eddy simulation (LES) model will be applied for further investigations.

Acknowledgements. The project was funded within the Priority Program 1167 "Quantitative Precipitation Forecast PQP (Praecipitationis Quantitativae Predictio)" by the German Science Foundation (DFG), second and third (Fo 226/19-1) period. The authors wish to acknowledge the support and data provision by the participants of the COPS experiment and the COPS Operations Center as well as Björn Brötz for many fruitful discussions and comments. Last but not least, the authors want to thank all people which took part in the field work, especially Andrei Serafimovich, Lukas Siebicke, Katharina Staudt, Johannes Lüers and Johannes Olesch.

Edited by: G. Vaughan

\section{References}

Aubinet, M., Grelle, A., Ibrom, A., Rannik, U., Moncrieff, J., Foken, T., Kowalski, A. S., Martin, P. H., Berbiger, P., Bernhofer, C., Clement, R., Elbers, J. A., Granier, A., Grünwald, T., Morgenstern, K., Pilegaard, K., Rebmann, C., Snijders, W., Valentini, R., and Vesala, T.: Estimates of the Annual Net Carbon and Water Exchange of Forests The EUROFLUX Methodology, Adv. Ecol. Res., 30, 113-176, 2000.

Baldocchi, D., Falge, E., Gu, L. H., Olson, R., Hollinger, D., Running, S., Anthoni, P., Bernhofer, C., Davis, K., Evans, R., Fuentes, J., Goldstein, A., Katul, G., Law, B., Lee, X. H., Malhi, Y., Meyers, T., Munger, W., Oechel, W., U, K. T. P., Pilegaard, K., Schmid, H. P., Valentini, R., Verma, S., Vesala, T., Wilson, K., and Wofsy, S.: FLUXNET: A new tool to study the temporal and spatial variability of ecosystem-scale carbon dioxide, water vapor, and energy flux densities, B. Am. Meteorol. Soc., 82, 2415-2434, 2001.

Banta, R. M.: Daytime Boundary-Layer Evolution over Mountainous Terrain. Part 1: Observations of the Dry Circulations, Mon. Weather. Rev., 112, 340-356, 1984.

Banta, R. M.: The role of mountain flows in making clouds, in: Atmospheric processes over complex terrain, edited by Blumen, W., vol. 23 (45) of Meteorological monographs, pp. 229-283, American Meteorological Society, 1990.

Barthlott, C., Corsmeier, U., Meißner, C., Braun, F., and Kottmeier, C.: The influence of mesoscale circulation systems on triggering convective cells over complex terrain, Atmos. Res., 81, 150-175, 2006.

Bergström, H. and Högström, U.: Turbulent exchange above a pine forest. II. Organized structures., Bound.-Lay. Meteorol., 49, 231263, 1989.

Betts, A. K., Ball, J. H., Beljaars, A. C. M., Miller, M. J., and Viterbo, P. A.: The land surface-atmosphere interaction: A review based on observational and global modeling perspectives, J. Geophys. Res.-Atmos., 101, 7209-7225, 1996.

Beyrich, F.: Mixing height estimation from sodar data - A critical discussion, Atmos. Environ., 31, 3941-3953, 1997.

Chen, F. and Avissar, R.: Impact of Land-Surface Moisture Variability on Local Shallow Convective Cumulus and Precipitation in Large-Scale Models, J. Appl. Meteorol., 33, 1382-1401, 1994.

Deardorff, J. W.: Convective Velocity and Temperature Scales for the Unstable Planetary Boundary Layer and for Rayleigh Convection, J. Atmos. Sci., 27, 1211-1213, 1970a.

Deardorff, J. W.: Preliminary Results from Numerical Integrations of the Unstable Planetary Boundary Layer, J. Atmos. Sci., 27, 1209-1211, 1970b.

Eigenmann, R.: Investigation of conditions initiating free convection using energy exchange measurements. COPS-experiment, Black Forest, 2007, Master's thesis, University of Bayreuth, Germany, 2008.

Foken, T.: The energy balance closure problem: An overview, Eco. Appl., 18, 1351-1367, 2008a.

Foken, T.: Micrometeorology, Springer, New York, 1st edn., 2008b.

Foken, T. and Wichura, B.: Tools for quality assessment of surfacebased flux measurements, Agr. Forest. Meteorol., 78, 83-107, 1996.

Foken, T., Göckede, M., Mauder, M., Mahrt, L., Amiro, B. D., and Munger J. W.: Post-field data quality control, in: Handbook of Micrometeorology: A Guide for Surface Flux Measurement and 
Analysis, edited by Lee, X., Massman, W., and Law, B., 181208, Kluwer, Dordrecht, 2004.

Foken, T., Wimmer, F., Mauder, M., Thomas, C., and Liebethal, C.: Some aspects of the energy balance closure problem, Atmos. Chem. Phys., 6, 4395-4402, 2006.

Gao, W., Shaw, R. H., and Paw U, K. T.: Observation of organized structures in turbulent flow within and above a forest canopy, Bound.-Lay. Meteorol., 47, 349-377, 1989.

Göckede, M., Rebmann, C., and Foken, T.: A combination of quality assessment tools for eddy covariance measurements with footprint modelling for the characterisation of complex sites, Agr. Forest. Meteorol., 127, 175-188, 2004.

Göckede, M., Markkanen, T., Hasager, C. B., and Foken, T.: Update of a footprint-based approach for the characterisation of complex measurement sites, Bound.-Lay. Meteorol., 118, 635-655, 2006.

Göckede, M., Foken, T., Aubinet, M., Aurela, M., Banza, J., Bernhofer, C., Bonnefond, J. M., Brunet, Y., Carrara, A., Clement, R., Dellwik, E., Elbers, J., Eugster, W., Fuhrer, J., Granier, A., Grunwald, T., Heinesch, B., Janssens, I. A., Knohl, A., Koeble, R., Laurila, T., Longdoz, B., Manca, G., Marek, M., Markkanen, T., Mateus, J., Matteucci, G., Mauder, M., Migliavacca, M., Minerbi, S., Moncrieff, J., Montagnani, L., Moors, E., Ourcival, J. M., Papale, D., Pereira, J., Pilegaard, K., Pita, G., Rambal, S., Rebmann, C., Rodrigues, A., Rotenberg, E., Sanz, M. J., Sedlak, P., Seufert, G., Siebicke, L., Soussana, J. F., Valentini, R., Vesala, T., Verbeeck, H., and Yakir, D.: Quality control of CarboEurope flux data - Part 1: Coupling footprint analyses with flux data quality assessment to evaluate sites in forest ecosystems, Biogeosciences., 5, 433-450, 2008.

Gurvich, A. S.: Experimental investigation of frequency spectra of the vertical wind velocity in the atmospheric surface layer, Dokl. Akad. Nauk SSSR, 132, 806-809, 1960.

Gurvich, A. S.: Spectra of the vertical wind-velocity fluctuations and their relation to micrometeorological conditions, Atmospheric Turbulence, (Proc. In-ta Fiziki Atmosf. Akad. Nauk SSSR, No. 4), 101-136, 1962.

Hanesiak, J. M., Raddatz, R. L., and Lobban, S.: Local initiation of deep convection on the Canadian prairie provinces, Bound.-Lay. Meteorol., 110, 455-470, 2004.

Hiller, R., Zeeman, M. J., and Eugster, W.: Eddy-covariance flux measurements in the complex terrain of an Alpine valley in Switzerland, Bound.-Lay. Meteorol., 127, 449-467, 2008.

Inagaki, A., Letzel, M. O., Raasch, S., and Kanda, M.: Impact of surface heterogeneity on energy imbalance: A study using LES, J. Meteorol. Soc. Jpn., 84, 187-198, 2006.

Jegede, O. O. and Foken, T.: A study of the internal boundary layer due to a roughness change in neutral conditions observed during the LINEX field campaigns, Theor. Appl. Climatol., 62, 31-41, 1999.

Kaimal, J. C., Wyngaard, J. C., Izumi, Y., and Cote, O. R.: Spectral characteristics of surface-layer turbulence, Q. J. Roy. Meteor. Soc., 98, 563-589, 1972.

Kalthoff, N., Binder, H. J., Kossmann, M., Vogtlin, R., Corsmeier, U., Fiedler, F., and Schlager, H.: Temporal evolution and spatial variation of the boundary layer over complex terrain, Atmos. Environ., 32, 1179-1194, 1998.

Kalthoff, N., Horlacher, V., Corsmeier, U., Volz Thomas, A., Kolahgar, B., Geiss, H., Mollmann Coers, M., and Knaps, A.: Influence of valley winds on transport and dispersion of airborne pollutants in the Freiburg-Schauinsland area, J. Geophys. Res.Atmos., 105, 1585-1597, 2000.

Kanda, M., Inagaki, A., Letzel, M. O., Raasch, S., and Watanabe, T.: LES study of the energy imbalance problem with Eddy covariance fluxes, Bound.-Lay. Meteorol., 110, 381-404, 2004.

Katul, G. G. and Chu, C. R.: A theoretical and experimental investigation of energy-containing scales in the dynamic sublayer of boundary-layer flows, Bound.-Lay. Meteorol., 98, 279-312, 1998.

Katul, G. G., Chu, C. R., Parlange, M. B., Albertson, J. D., and Ortenburger, T. A.: Low-wavenumber spectral characteristics of velocity and temperature in the atmospheric surface layer, J. Geophys. Res., 100, 14243-14255, 1995.

Kolmogorov, A. N.: Rassejanie energii pri lokolno-isotropoi turbulentnosti, Dokl. AN. SSSR., 32, 22-24, 1941.

Kossmann, M. and Fiedler, F.: Diurnal momentum budget analysis of thermally induced slope winds, Meteorol. Atmos. Phys., 75 195-215, 2000.

Kossmann, M., Vogtlin, R., Corsmeier, U., Vogel, B., Fiedler, F., Binder, H. J., Kalthoff, N., and Beyrich, F.: Aspects of the convective boundary layer structure over complex terrain, Atmos. Environ., 32, 1323-1348, 1998.

Kottmeier, C., Kalthoff, N., Corsmeier, U., Barthlott, C., van Baelen, J., Behrendt A., Behrendt, R., Blyth, A., Coulter, R., Crewell, S., Dorninger, M., Foken, T., Hagen, M., Hauck, C., Höller, H., Konow, H., Kunz, M., Mahlke, H., Mobbs, S., Richard, E., Steinacker, R., Weckwerth, T., and Wulfmeyer, V.: Mechanisms initiating convection during the COPS experiment, Meteorol. Z., 17, 931-948, 2008.

Liebethal, C. and Foken, T.: Evaluation of six parameterization approaches for the ground heat flux, Theor. Appl. Climatol., 88, 43-56, 2007.

Lugauer, M. and Winkler, P.: Thermal circulation in South Bavaria climatology and synoptic aspects, Meteorol. Z., 14, 15-30, 2005.

Maraun, D. and Kurths, J.: Cross Wavelet Analysis. Significance Testing and Pitfalls, Nonlinear. Proc. Geoph., 11, 505-514, 2004.

Maraun, D., Kurths, J., and Holschneider, M.: Nonstationary Gaussian Processes in Wavelet Domain: Synthesis, Estimation and Significance Testing, Phys. Rev. E., 75, 016707, doi:10.1103/PhysRevE.75.016707, 2007.

Mauder, M. and Foken, T.: Documentation and instruction manual of the Eddy covariance software package TK2, Work Report University of Bayreuth, Department of Micrometeorology, 26, ISSN: 1614-8916, 42 pp., 2004.

Mauder, M., Liebethal, C., Göckede, M., Leps, J. P., Beyrich, F., and Foken, T.: Processing and quality control of flux data during LITFASS-2003, Bound.-Lay. Meteorol., 121, 67-88, 2006.

Mayer, J. C., Staudt, K., Gilge, S., Meixner, F. X., and Foken, T.: The impact of free convection on late morning ozone decreases on an Alpine foreland mountain summit, Atmos. Chem. Phys., 8, 5941-5956, 2008.

Meißner, C., Kalthoff, N., Kunz, M., and Adrian, G.: Initiation of shallow convection in the Black Forest mountains, Atmos. Res., 86, 42-60, 2007.

Metzger, S., Foken, T., Eigenmann, R., Kurtz, W., Serafimovich, A., Siebicke, L., Olesch, J., Staudt, K., and Lüers, J.: COPS experiment, Convective and orographically induced precipitation study, 01 June 2007 - 31 August 2007, Documentation, Work Report University of Bayreuth, Department of Micrometeorology, 34, 
ISSN 1614-8916, 72 pp., 2007.

Monin, A. S. and Yaglom, A. M.: Statistical Fluid Mechanics, Volume II: Mechanics of Turbulence, MIT Press, Cambridge, Massachusetts, USA, and London, England, UK, 1975.

Pielke, R. A.: Influence of the spatial distribution of vegetation and soils on the prediction of cumulus convective rainfall, Rev. Geophys., 39, 151-177, 2001.

Raabe, A.: On the relation between the drag coefficient and fetch above the sea in the case of off-shore wind in the near-shore zone, Z. Meteorol., 33, 363-367, 1983.

Rabin, R. M., Stadler, S., Wetzel, P. J., Stensrud, D. J., and Gregory, M.: Observed Effects of Landscape Variability on Convective Clouds, B. Am. Meteorol. Soc., 71, 272-280, 1990.

Rannik, U., Aubinet, M., Kurbanmuradov, O., Sabelfeld, K. K., Markkanen, T., and Vesala, T.: Footprint analysis for measurements over a heterogeneous forest, Bound.-Lay. Meteorol., 97, 137-166, 2000.

Rannik, U., Markkanen, T., Raittila, J., Hari, P., and Vesala, T.: Turbulence statistics inside and over forest: Influence on footprint prediction, Bound.-Lay. Meteorol., 109, 163-189, 2003.

Raymond, D. and Wilkening, M.: Mountain-Induced Convection under Fair Weather Conditions, J. Atmos. Sci., 37, 2693-2706, 1980.

Rebmann, C., Göckede, M., Foken, T., Aubinet, M., Aurela, M., Berbigier, P., Bernhofer, C., Buchmann, N., Carrara, A., Cescatti, A., Ceulemans, R., Clement, R., Elbers, J. A., Granier, A., Grunwald, T., Guyon, D., Havrankova, K., Heinesch, B., Knohl, A., Laurila, T., Longdoz, B., Marcolla, B., Markkanen, T., Miglietta, F., Moncrieff, J., Montagnani, L., Moors, E., Nardino, M., Ourcival, J. M., Rambal, S., Rannik, U., Rotenberg, E., Sedlak, P., Unterhuber, G., Vesala, T., and Yakir, D.: Quality analysis applied on eddy covariance measurements at complex forest sites using footprint modelling, Theor. Appl. Climatol., 80, 121-141, 2005.

Savelyev, S. A. and Taylor, P. A.: Internal boundary layers: I. Height formulae for neutral and diabatic flows, Bound.-Lay. Meteorol., 115, 1-25, 2005.

Schwitalla, T., Bauer, H.-S., Wulfmeyer, V., and Zaengl, G.: Systematic errors of QPF in low-mountain regions as revealed by MM5 simulations, Meteorol. Z., 17, 903-919, 2008.

Segal, M. and Arritt, R. W.: Nonclassical mesoscale circulations caused by surface sensible heat-flux, B. Am. Meteorol. Soc., 73, 1593-1604, 1992.

Shen, S. H. and Leclerc, M. Y.: How large must surface inhomogeneities be before they influence the convective boundary layer structure? A case study, Q. J. Roy. Meteor. Soc., 121, 12091228, 1995.

Staudt, K.: Determination of the atmospheric boundary layer height in complex terrain during SALSA 2005, Master's thesis, University of Bayreuth, Germany, 2006.
Steinfeld, G., Letzel, M. O., Raasch, S., Kanda, M., and Inagaki, A.: Spatial representativeness of single tower measurements and the imbalance problem with eddy-covariance fluxes: results of a large-eddy simulation study, Bound.-Lay. Meteorol., 123, 77-98, 2007.

Stull, R. B.: An introduction to boundary layer meteorology, Atmospheric sciences library, Kluwer Academic Publishers, Dordrecht, The Netherlands, 1988.

Stull, R. B.: Meteorology for scientists and engineers, Brooks/Cole, Pacific Grove, California, 2. edn., 2000.

Thomas, C. and Foken, T.: Detection of long-term coherent exchange over spruce forest using wavelet analysis, Theor. Appl. Climatol., 80, 91-104, 2005.

Whiteman, C. D.: Observations of thermally developed wind systems in mountainous terrain, in: Atmospheric processes over complex terrain, edited by Blumen, W., vol. 23 (45) of Meteorological monographs, 5-42, American Meteorological Society, Boston, Massachusetts, USA, 1990.

Wulfmeyer, V., Behrendt, A., Adrian, G., Althausen, D., Aoshima, F., van Baelen, J., Barthlott, C., Bauer, H. S., Blyth, A., Brandau, C., Corsmeier, U., Craig, G., Crewell, S., Dick, G., Dorninger, M., Dufournet, Y., Ehret, G., Engelmann, R., Flamant, C., Foken, T., Hauck, C., Girolamo, P. D., Graß1, H., Grzeschik, M., Handwerker, J., Hagen, M., Hardesty, R. M., Junkermann, W., Kalthoff, N., Kiemle, C., Kottmeier, C., Krauss, L., Long, C., Lelieveld, J., Madonna, F., Miller, M., Mobbs, S., Neininger, B., Pal, S., Peters, G., Radlach, M., Richard, E., Rotach, M., Russchenberg, H., Schlüssel, P., Schumann, U., Simmer, C., Steinacker, R., Turner, D., Vogt, S., Volkert, H., Weckwerth, T., Wernli, H., Wieser, A., and Wunraum, C.: Convective and Orographically-induced Precipitation Study. COPS Field Report 2.1., https://www.uni-hohenheim.de/spp-iop/documents/ COPSFieldReport2.pdf, 2007.

Wulfmeyer, V., Behrendt, A., Bauer, H.-S., Kottmeier, C., Corsmeier, U., Blyth, A., Craig, G., Schumann, U., Hagen, M., Crewell, S., Di Girolamo, P., Flamant, C., Miller, M., Montani, A., Mobbs, S., Richard, E., Rotach, M. W., Arpagaus, M., Russchenberg, H., Schluessel, P., Koenig, M., Gaertner, V., Steinacker, R., Dorninger, M., Turner, D. D., Weckwerth, T., Hense, A., and Simmer, C.: The Convective and Orographicallyinduced Precipitation Study: A Research and Development Project of the World Weather Research Program for Improving Quantitative Precipitation Forecasting in Low-Mountain Regions, B. Am. Meteorol. Soc., 89, 1477-1486, 2008.

Zubkovskii, S. L.: Frequency spectra of the horizontal windvelocity fluctuations in the atmospheric surface layer, Izv. Akad. Nauk SSSR, Ser. Geofiz, No. 10, 1425-1433, 1962. 